\title{
Combining distribution modelling and non-invasive genetics to improve range shift forecasting
}

\author{
Frederico Mestre ${ }^{\mathrm{a}, *}$, Ricardo Pita ${ }^{\mathrm{a}}$, Joana Paupério ${ }^{\mathrm{b}}$, Filipa M.S. Martins ${ }^{\mathrm{b}}$, \\ Paulo Célio Alves ${ }^{\mathrm{b}, \mathrm{c}, \mathrm{d}}$, António Mira ${ }^{\mathrm{a}}$, Pedro Beja ${ }^{\mathrm{b}}$ \\ ${ }^{a}$ CIBIO/InBio, Centro de Investigação em Biodiversidade e Recursos Genéticos, Pólo de Évora, Universidade de Évora, Núcleo da Mitra, Apartado 94, \\ 7002-554 Évora, Portugal \\ b CIBIO-UP, Centro de Investigação em Biodiversidade e Recursos Genéticos, Universidade do Porto, InBIO Laboratório Associado, Campus Agrário de Vairão, \\ 4485-661 Vairão, Portugal \\ ${ }^{\mathrm{c}}$ Departamento de Biologia, Faculdade de Ciências da Universidade do Porto, Rua do Campo Alegre s/n, 4169-007 Porto, Portugal \\ ${ }^{\mathrm{d}}$ Wildlife Biology Program, University of Montana, Missoula, MT 59812, USA
}

\section{A R T I C L E I N F O}

\section{Article history:}

Received 23 June 2014

Received in revised form 18 October 2014

Accepted 17 November 2014

\section{Keywords:}

Climate change

Ecological niche

Microtus cabrerae

Range margins

Range shift

Cytochrome-b gene

\begin{abstract}
A B S T R A C T
Forecasting species range shifts under climate change is critical to adapt conservation strategies to future environmental conditions. Ecological niche models (ENMs) are often used to achieve this goal, but their accuracy is limited when species niches are inadequately sampled. This problem may be tackled by combining ENM with field validation to fine-tune current species distribution, though the traditional methods are often time-consuming and the species ID inaccurate. Here we combine ENM with novel field validation methods based on non-invasive genetic sampling to forecast range shifts in the globally near-threatened Cabrera vole (Microtus cabrerae). Using occurrence records mapped at $10 \mathrm{~km} \times 10 \mathrm{~km}$ resolution, we built the first ENM (ENM1) to estimate the current species distribution. We then selected 40 grid squares with no previous data along the predicted range margins, and surveyed suitable habitats through presencesign searches. Faecal samples visually assigned to the species were collected for genetic identification based on the mitochondrial cytochrome- $b$ gene, which resulted in 19 new grid squares with confirmed presence records. The second model (ENM2) was built by adding the new data, and species distribution maps predicted by each model under current and future climate change scenarios were compared. Both models had high predictive ability, with strong influence of temperature and precipitation. Although current distribution ranges predicted by each model were quite similar, the range shifts predicted under climate change differed greatly when using additional field data. In particular, ENM1 overlooked areas identified as important by ENM2 for species conservation in the future. Overall, results suggest that combining ENM with non-invasive genetics may provide a cost-effective approach in studies regarding species conservation under environmental change.
\end{abstract}

(c) 2014 Elsevier B.V. All rights reserved.

\section{Introduction}

There is growing evidence that many species will change their current ranges in response to climate change. These range shifts, may have multiple conservation implications on, for instance, the design of reserve networks (Hannah, 2008; Hannah et al., 2002), assisted colonization approaches (Hoegh-Guldberg et al., 2008), and habitat restoration priorities (Mawdsley et al., 2009).

\footnotetext{
* Corresponding author. Tel.: +351282338232.

E-mail address: mestre.frederico@gmail.com (F. Mestre).
}

Species range shifts are caused by the expansion or contraction of favourable climatic conditions, and typically emerge from extinction-colonization processes mostly driven by the species physiological tolerances, dispersal abilities, and habitat availability along their distribution limits (Anderson et al., 2009; Thomas, 2010; Walther et al., 2002). Generally, species tend to occupy newly available patches at their expanding margins, being more likely to become locally extinct at the retracting margin (Anderson et al., 2009). Support for such climate-induced range dynamics in many plants and animals has led to the recognition that effective conservation planning should move from a static to a dynamic approach. Accurate projections on potential species distribution 